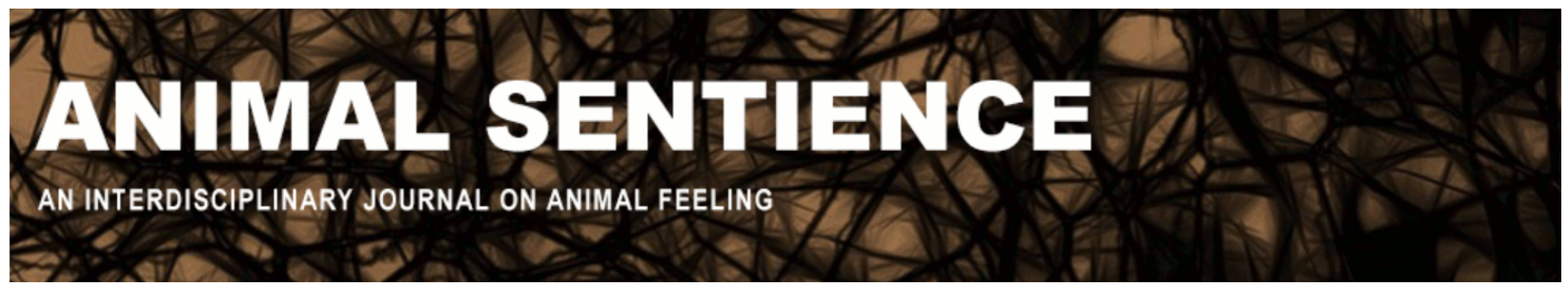

Elwood, Robert W. (2016) Might insects experience pain?. Animal Sentience 9(18)

DOI: $10.51291 / 2377-7478.1156$

Date of submission: 2016-09-02

Date of acceptance: 2016-09-09

(c)

This article has appeared in the journal Animal

Sentience, a peer-reviewed journal on animal

cognition and feeling. It has been made open access,

free for all, by WellBeing International and deposited

in the WBI Studies Repository. For more information,

please contact

wbisr-info@wellbeingintl.org.

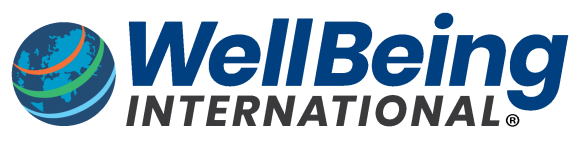

SOLUTIONS FOR PEOPLE, ANIMALS AND ENVIRONMENT 


\title{
Might insects experience pain?
}

Commentary on Klein \& Barron on Insect Experience

\author{
Robert W. Elwood \\ School of Biological Sciences \\ Queen's University, Belfast
}

\begin{abstract}
The aim of this commentary is to expand the discussion about subjective experience to other arthropods, notably crustaceans. Various species of crustaceans show responses consistent with their feeling pain. Hermit crabs also show prolonged investigation of new shells. They clearly attend to and integrate information from a wide variety of sources that enable them to evaluate the quality of the new shell relative to their current shell. These observations too are consistent with their having subjective experience.
\end{abstract}

Robert W. Elwood, Emeritus Professor of Animal Behaviour, Queen's University, Belfast, works on information-gathering, motivation, aggression and pain. https://scholar.google.co.uk/citations?user=JoEJgS UAAAAJ\&hl=en

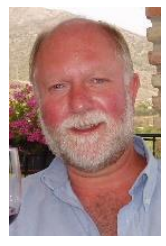

Subjective experiences are "a basic awareness of the world without further reflection on that awareness" (Klein \& Barron (2016)) (K\&B). In vertebrates this ability is implemented by subcortical structures. K \& B make a convincing case that structures with similar functions are also present in the much smaller brains of insects. Such structures are not present in jellyfish or nematode worms, and a case is made that these taxa do not have a basic awareness. They appear to act with little or no centralized decision-making ability. Unable to relate to specific environmental locations, they do not perform spatiotemporal modelling and thus their search is random. A key ability of many mobile animals is not just to detect environmental changes but to distinguish between real changes and those brought about by the animal's own movement. Insects and vertebrates both have this ability. The structures that underlie this integration have a long evolutionary history. They presumably predate the split between arthropods and chordates because of the similarities in the different arthropod groups (e.g., insects, crustaceans and spiders). According to $\mathrm{K} \& \mathrm{~B}$, both phyla "have a perspective on the world with a unique phenomenological feel." That is, insects (as well as other arthropods) have feelings too.

$\mathrm{K} \& \mathrm{~B}$ derive these conclusions from a detailed comparison of the complex brain structures and functions of arthropods (insects) and vertebrates. Their impressive review gives insight into what are presumed to be the relative abilities of the two phyla. I say "presumed" because of the accepted difficulty of studying feelings in animals (Stamp Dawkins 2012.) I attempt nevertheless to evaluate what $K \& B^{\prime}$ s view entails for the perception of potential tissue damage and whether that might involve the feeling that we call pain.

Although K \& B's target article itself does not mention it explicitly, questions about pain have already been raised in several of the subsequent commentaries (e.g., Adamo 2016b, Fischer 2016, Lamey 2016, Tye 2016). The possibility of pain in insects is also the topic of a recent 
paper by one of the commentators (Adamo 2016a). I will try to assess what we can conclude from this work. My own experience is with decapod crustaceans rather than insects. I use experimental approaches to test whether their responses to noxious stimuli are consistent with the idea that they are feeling pain (e.g., Elwood \& Appel 2009, Barr et al. 2008, Magee \& Elwood 2013, 2016a,b).

A key problem with studying pain in animals is that they might have purely reflexive nociceptive responses without the associated feeling of pain (Elwood 2011, Sneddon et al. 2014). Nematodes, for example, do have the ability to detect noxious stimuli and respond by moving away (Whittenburg \& Baumeister 1999). K \& B do not infer from this that feelings occur in this group. This nociceptive ability nevertheless provides protection from the damaging effects of those noxious stimuli. One may wonder what advantage is gained by the ability to feel pain. The most persuasive hypothesis is that pain would enhance the salience of the stimulus that caused it and enable the animal to learn to rapidly avoid that stimulus (Sneddon et al. 2014). Thus the benefit would arise from reducing the reoccurrence of tissue damage. In contrast, with nociception alone, lacking awareness of the stimulus, rapid avoidance learning would be less likely. The negative affective state of pain is accordingly predicted to include awareness, which provides the strong motivation to escape the stimulus in the short term and to avoid it in the future. Where there is sentience we would expect to see avoidance and discrimination learning if the animal is repeatedly exposed to noxious stimuli. This is indeed found in various insects (Agarwal 2011) and decapods (Magee \& Elwood 2013), but only if the stimuli to be discriminated are presented simultaneously and not sequentially (Magee \& Elwood 2016a). Electric shock also changes risk-taking behaviour in crayfish in ways similar to anxiety in vertebrates. Treatment with anxiolytic drugs made for human use also reduces such anxiety in crayfish (Fossat et al. 2014, 2015). Subjective experience thus provides long-term protection.

Attention to particular stimuli can also be inferred when an animal rubs or grooms the part of the body to which the noxious stimulus was applied. In prawns we see prolonged grooming and rubbing of a specific antenna that was subject to noxious chemical application (Barr et al. 2008). Hermit crabs groom their abdomen if they receive electric shock there (Appel \& Elwood 2009a,b) and brown crabs that have had a claw pulled off, as in commercial fishery practice, pick at their wound (Claire McCambridge, personal communication). These arthropods appear to know the location of the noxious stimulus and direct their behaviour to that location, suggesting that they are attending to the feeling of the wound. These activities are consistent with the idea of arthropods having a subjective experience.

$\mathrm{K} \& \mathrm{~B}$ also consider subjective experience to be an aid in decision-making processes. Finely tuned decisions that weigh and trade off different motivations can be observed in decapods in response to noxious stimuli. Hermit crabs housed in poor quality shells are more likely to abandon them when they receive shock on the abdomen than crabs living in high quality shells (Elwood \& Appel 2009). Hermit crabs are also less likely to abandon a shell if shocked when there are odours of predators in the water (compared to when there is no odour or only the odour of non-predators) (Magee \& Elwood 2016b). Thus, in both cases the crabs are not acting by pure reflex; rather, a decision-making process is evident that is consistent with the idea of a subjective experience. 
When hermit crabs gather and use information about empty shells for potential occupancy, the information is drawn from multiple sources over time (reviewed by Elwood 1995). Information about shell species and hence shape is gathered during the approach to the shell. This is followed by a series of activities during which the crab palpates the exterior of the shell, gaining information about shape and size. The crab then repeatedly inserts its chelipeds into the shell aperture and gathers information about obstructions such as sand within the shell. If sand is detected, the crab turns the shell to pour it out but larger particles are lifted out with the chelipeds. The chelped exploration within the shell gathers further information about size and shape. Depending on the suitability of the shell for that individual compared to its current shell, the crab may or may not move into the new shell. If it moves in, it moves about within the shell and may then go through a series of activities apparently assessing its original shell with its chelipeds. Eventually a decision is made as to which shell will be occupied. Hence the crab appears to attend to and integrate information from different sources to make this complex decision. It is difficult to imagine how this could be achieved without some form of subjective experience (but see critique by Mallatt \& Feinberg 2016).

$\mathrm{K} \& \mathrm{~B}$ note briefly that robots that have hitherto been assumed to lack subjective experience can nevertheless act in ways similar to insects. This robot analogy has been specifically used to discount the possibility of pain experience in insects (Adamo 2016a). Robots can certainly be designed to exhibit pain-like behaviour. For example, in the training of dental students robotic models of the human head have been programmed to behave like humans in pain during dental treatment. Clearly these robots do not feel pain yet nevertheless react to clumsy treatment by prospective dentists as if they did. If robots can be programmed in this way to appear as if they feel pain then - so the argument by analogy goes - insects too may have simple systems to respond to noxious stimuli without the subjective experience. There is a major flaw in this argument, however: Robots result from intelligent design in which highly skilled engineers produce a system that mimics humans in pain. By contrast, insects result from natural selection; thus their behaviour should have benefits in terms of fitness that outweigh the costs. I cannot imagine what benefits insects or other arthropods might gain from behaving as if they were in pain if they were not actually having a subjective experience. Indeed, given the long time since the divergence of arthropods from the lines that gave rise to vertebrates, one must assume that they mimicked something that did not exist for hundreds of million years.

Pain is often dismissed in most invertebrates on the grounds that their brains are too small and simple (Elwood 2011). K \& B's work suggests that this dismissal should not be accepted so readily. They argue instead that the nervous system of insects and other arthropods is complex and has functions similar to those of vertebrates with respect to subjective experience. They specify those taxonomic groups in which pain might be expected to occur and those in which it would not. In this K \& B have done a good job. Of course, none of these studies proves that arthropods feel pain. My own conclusion is that it is indeed possible that arthropods experience pain and that the work of Klein \& Baron is consistent with that possibility. 


\section{References}

Adamo, S.A. (2016a) Do insects feel pain? A question at the intersection of animal behaviour, philosophy and robotics. Animal Behaviour, 118, 75-79.

Adamo, S.A. (2016b) Subjective experience in insects: Definitions and other difficulties. Animal Sentience 2016.127.

Agarwal, M., Giannoni Guzmán, M., Morales-Matos, C., Del Valle Díaz, R.A., Abramson, C.I. \& Giray, T. (2011) Dopamine and octopamine influence avoidance learning of honey bees in a place preference assay. PLoS One, 6, e25371.

Appel, M. \& Elwood, R.W. (2009a) Motivational trade-offs and the potential for pain experience in hermit crabs. Applied Animal Behaviour Science, 119, 120-124.

Appel, M. \& Elwood R.W. (2009b) Gender differences, responsiveness and memory of a potentially painful event in hermit crabs. Animal Behaviour, 78, 1373-1379.

Barr, S., Laming, P.R., Dick, J.T.A. \& Elwood, R.W. (2008) Nociception or pain in a decapod crustacean? Animal Behaviour, 75, 745-751.

Elwood, R.W. (1995) Motivational change during resource assessment in hermit crabs. Journal of Experimental Marine Biology and Ecology, 193, 41-55.

Elwood, R.W. (2011) Pain and suffering in invertebrates? ILAR Journal, 52, 175-184.

Elwood, R. W. \& Appel, M. (2009) Pain in hermit crabs? Animal Behaviour 77, 1243-1246.

Fischer, B. (2016) What if Klein \& Barron are right about insect sentience? Animal Sentience 2016.115.

Fossat, P., Bacque-Cazenave J., De Deurwaerdere P., Cattaert D. \& Delbecque, J-P. (2015) Serotonin, but not dopamine, controls stress response and anxiety-like behavior in crayfish, Procambarus clarkii. Journal of Experimental Biolology, 218, 2745-2752.

Fossat, P., Bacque-Cazenave, J., De Deurwaerdere, P., Delbecque J-P., \& Cattaert D. (2014) Anxiety-like behavior in crayfish is controlled by serotonin. Science, 344, 1293 e1297.

Klein, C. \& Barron, A.B. (2016) Insects have the capacity for subjective experience. Animal Sentience 2016.100.

Lamey, A. (2016) Subjective experience and moral standing. Animal Sentience 2016.114.

Magee, B. \& Elwood, R.W. (2013) Shock avoidance by discrimination learning in the shore crab (Carcinus maenas) is consistent with a key criterion for pain. Journal of Experimental Biology, 216, 353-358.

Magee, B. \& Elwood R.W. (2016a) No discrimination shock avoidance with sequential presentation of stimuli but shore crabs still reduce shock exposure. Biology Open.

Magee B. \& Elwood R.W. (2016b) Trade-offs between predator avoidance and electric shock avoidance in hermit crabs demonstrate a non-reflexive response to noxious stimuli consistent with prediction of pain. Behavioural Processes.

Mallatt, J. \& Feinberg, T.E. (2016) Insect consciousness: Fine-tuning the hypothesis. Animal Sentience 2016.118.

Sneddon, L.U., Elwood, R.W., Adamo, S.A. \& Leach, M.C. (2014) Defining and assessing animal pain. Animal Behaviour, 97, 202-212.

Stamp Dawkins, M. (2012) Why animals matter: Animal consciousness, animal welfare, and human well-being. Oxford, UK: Oxford University Press.

Tye, M. (2016) Are insects sentient? Animal Sentience 2016.111.

Whittenburg, N. \& Baumeister, R. (1999) Thermal avoidance in Caenorhabditis elegans: An approach to the study of nociception. Proceedings of the National Academy of Sciences of the United States of America, 96, 10477-10482. 